\title{
Equalized Load Shaping for Demand Side Management using Memetic Algorithm
}

\author{
C. Bharathi, V. Vijaya Kumar
}

\begin{abstract}
During rush hour, the electricity usage will be very high. It can be reduced by flexible load shaping. Load shaping is a technique used in smart grid for demand side management. In general two akinds of loads are there such as shiftable and non-shiftable load. Shiftable load can be shifted anywhere in the time slot. But non - shiftable loads should always run throughout the allotted time. So based on the shiftable loads, load shaping technique is carried out. It will be used to obtain the objective of equalized utilization of power in different areas such as industrial, commercial and residential area. Local search Memetic Algorithm, a novel technique in Evolutionary Algorithm, is used and it has provided the reduction of power wastage by and equalized power utilization.
\end{abstract}

Index Terms: Demand Side Management, Load shaping, Memetic Algorithm, Smart Grid.

\section{INTRODUCTION}

Integration of Smart Grid with Information and Communication Technologies (ICT) improves the quantity as well as the quality of the modern electrical grid [1]. For the distribution or scheduling, ICT have to be integrating with supply side, demand side and also with all the devices (loads) in Smart Grid Network [2]. Here, scheduling is not only meant for power generation and also for the load. Scheduling the load from peak hour to non-rush hour will provide the users to utilize the electricity efficiently [3].

Demand Side Management (DSM) shows a vital part in the reduction of power consumption [4]. There are six load curves in DSM [5]. They are load growth, load reduction, flexible load shaping, load shifting, valley filling ans peak clipping. Load growth is for increasing power consumption for certain period [6]. Load reduction is for conserving power. By suspending the power supply power conservation can be achieved. Flexible load shaping is for distribution of only few loads from peak hour to non-rush hour. Load shifting is for reduction and transformation of entire loads from peak hour to non-rush hour. Valley filling is for building up of all loads to the off-peak hour. Peak clipping is to reduce entire loads from peak hour.

Flexible load shaping gives the better power utilization than the other load curves [7]. Without clipping the entire loads from rush hour and build it to the off-peak hour, it will shift only limited no. of loads. So the power conservation and growth load can be avoided.In general two types of loads are

Revised Manuscript Received on July 10, 2019.

C. Bharathi, Research Scholar, School of Computing and Engineering, Vellore Institute of Technology, Chennai, Tamil Nadu, India.

V. Vijayakumar, Professor, School of Computing and Engineering, Vellore Institute of Technology, Chennai, Tamil Nadu, India. there such as shiftable load and non-shiftable load. Shiftable loads are the devices which will be shifted anywhere in the

given time slot. But non - shiftable loads should always run throughout the allotted time.

The current research includes the related works about the importance of Evolutionary and Memetic Algorithm in section 2. Memetic Algorithm and its major role in Smart Grid DSM is given in section 3. Section 4 explains the evaluation of disparity in fitness functions. Conclusion and work to be done later is discussed in section 5 .

\section{RELATED WORKS}

Evolutionary Algorithms are pervasive [8] and it can be implemented in many problems of various domains such as machine learning algorithm, optimization techniques, operational research, automatic programming, bioengineering and other social problems. It also describes the problem is not known and the values at certain parameters are obtained from simulations. Among all the other optimization techniques multi-modal functions can be dealt with Evolutionary Algorithms.

If Genetic Algorithms (GA) does local search then it is called Memetic Algorithm [9]. Memetic Algorithm is a standardized framework for bearing Memetic and GA [10]. Memetic Algorithm is given as a meme which is a unit of information that mimics itself as people exchange ideas [11]. Passing of gene and meme is having a main difference that gene gets passed on whole but before passing meme it should be processed based on the understanding of that particular person's thinking. If a local optimizer is used in GA, it does a local genetic search among all the local optimal solutions which is called Memetic Algorithm [12]. GA uses crossover and mutation to reproduce children outside these local optimal solutions. After that the optimizer will reproduce the final children.

Roulette Wheel selection was compared for both algorithmsMemetic Algorithm and GA [13]. Memetic Algorithmjoins quicker than GA still it generates various optimal solutions than GA generates by the percentage of 4.9, but time taken for each iteration in GA is lesser than the percentage of 35.9 than Memetic Algorithm. In terms of optimal solution and accuracy, Memetic Algorithm is so far proficient than the GA. As it falls under NP hard problems, we can conclude that Memetic Algorithm is highly suitable for it. 


\section{ALGORITHM DESCRIPTION}

If a problem does not have a heuristic solution or it produces the unsuitable results then the evolutionary approach can be used. It will give the satisfactory results. Also it can be associated with other optimization algorithms

Memetic Algorithm is the combination of Evolutionary Algorithm and local search. Like Evolutionary Algorithm, here there is an additional task of local search followed by selection, crossover and mutation. Fig. 1 depicts the flow chart of Memetic Algorithm

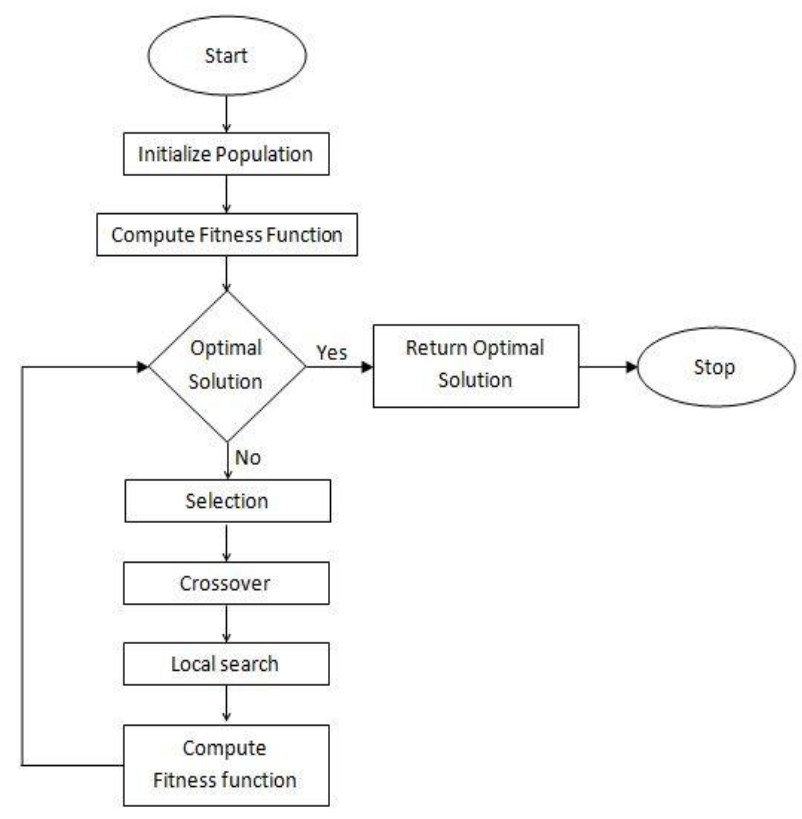

Fig. 1 Memetic Algorithm Flowchart

\section{A. Demand Side Management with Memetic Algorithm}

The best solution is provided by Memetic Algorithm based on the flexible load shaping objective function [7]

where $t=$ no. of time step,

$$
\text { Minimize } \sum_{i=1}^{t} \sum_{k=1}^{L} l_{k^{*}} p_{i}
$$

$L=$ no. of device types,

$l=$ total no. of loads in individual device type and

$p=$ power of individual device in $\mathrm{kWh}$.

$$
\text { Fitness Function }=1+\frac{1}{\sum_{i=1}^{t} \sum_{k=1}^{L} l_{k} p_{i}}
$$

Equations (1) and (2) denotes the objective function and Fitness Function (FF) [7] of the Memetic Algorithm.

\section{Algorithm 1. Equalized Load Shaping for Demand Side Management using Memetic Algorithm (MA-DSM)}

From the table of devices take device types ' $L$ ', no. of loads ' $l$ ' and consumption of power ' $p$ '

while $1<L<n$ do

while $0<l<m$ do

1. Compute the overall power consumption $(p)$ of no. of loads $(l)$

2. Initialize population

3. Calculate FF of DSM without MA

4. Optimal solution

\section{Memetic Algorithm steps:}

i. Selection of best chromosomes founded on the minimal ' $p$ ' in rush hour ' $p$ '

ii. For time slot ' $t$ ', carry out Arithmetic crossover for ' $l$ ' based on ' $p$ '.

iii. Do local search and select the best chromosome from new population <local search>

iv. Calculate FF matrix of the ' $l$ ' with minimal ' $p$ ' during ' $p h$ '. <optimal solution $(\mathrm{OS})>$

6. Compare both optimal solutions obtained in step 4. and 5.iv.

7. Return the best OS

end while

Repeat the process for every ' $L$ ' and then choose the best optimal FF.

end while

Algortihm 1 gives us the Memtic Algorithm for Equalized Load shaping in Demand Side Management (MA-DSM). The process of reproduction includes 4 significant steps. They are selection, crossover, local search and calculating FF. By using minimal 'p' in rush hour 'ph', the best chromosomes will be selected. By the process of crossover, new offspring are generated from these chromosomes. From 4 types of crossover methods arithmetic crossover is chosen. Finding the best chromosome from the new offspring for the optimization process is called local search. Compute the fitness function with MA-DSM. Compare it with the fitness function of DSM without MA and return the best optimal solution. For new population, best optimal solution should be obtained by repeating all the process for $\mathrm{n}$ times.

\section{SIMULATION AND RESULTS}

MATLAB is used to carry out the simulations for three diverse areas. Although Memetic Algorithm takes more time than GA, the result will be highly efficient. Here the result is compared with both Heuristic based Evolutionary algorithm (HDSM) [14] and GA-DSM [7]. For comparison purpose Table 1, 3 and 5 are taken as input datasetas given [14]. GA-DSM details in Table 2, 4 and 6 are taken [7].

\section{A. Industrial Area:}

I. contains the data of Industrial area. It consists of both shiftable and non-shiftable loads. Non-shiftable loads: cannot be exposed to MA-DSM. For eg: Induction motor and arc furnace. Population is considered from shiftable loads and are exposed to the MA-DSM. Computation of FF and its average is carried out using DSM without MA and MA-DSM respectively. Fig. 2 gives the result of that comparison.

Fig. 2 clearly depicts the average FF of DSM without MA in $1^{\text {st }}$ three slots which are peak hours others are off-peak hours. To obtain the optimized solution, few loads are shifted to non-rush hours that is signified in the average FF with MA-DSM. 
Average of peak demand power reduction is $18.86 \%$ before and after the applyingMA-DSM shown in Fig. 3. HDSMand GA-DSM gives the power reduction of $14.2 \%$ and $23.84 \%$ respectively. Hence the given MA-DSM gains beyond HDSM and within GA-DSM. It means that load shaping does not shift more loads to the off-peak hour. So off-peak hour does not become peak. MA-DSM tried to equally redistribute the loads and achieved its objective. Let us compare the increase and decrease of power consumption using GA-DSM and MA-DSM in II. Negative sign (-) and positive sign $(+)$ indicates the decrease and increase of power respectively.

I. Data of Industrial Area Loads

\begin{tabular}{|c|l|c|c|c|c|c|c|c|}
\hline \multirow{2}{*}{ S1.No } & \multirow{6}{*}{ Device Types } & \multicolumn{6}{|c|}{ Device Power Consumption (kWh) } & \multirow{2}{*}{ Number of Devices } \\
\cline { 3 - 8 } & & $\begin{array}{c}1 \text { st } \\
\text { Hour }\end{array}$ & $\begin{array}{c}2 \text { 2nd } \\
\text { Hour }\end{array}$ & $\begin{array}{c}\text { 3rd } \\
\text { Hour }\end{array}$ & $\begin{array}{c}4 \text { th } \\
\text { Hour }\end{array}$ & $\begin{array}{c}5 \text { th } \\
\text { Hour }\end{array}$ & 6th Hour & \\
\hline 1 & Water Heater & 12.5 & 12.5 & 12.5 & 12.5 & - & - & 39 \\
\hline 2 & Welding Machine & 25 & 25 & 25 & 25 & 25 & - & 35 \\
\hline 3 & Fan/AC & 30 & 30 & 30 & 30 & 30 & - & 16
\end{tabular}

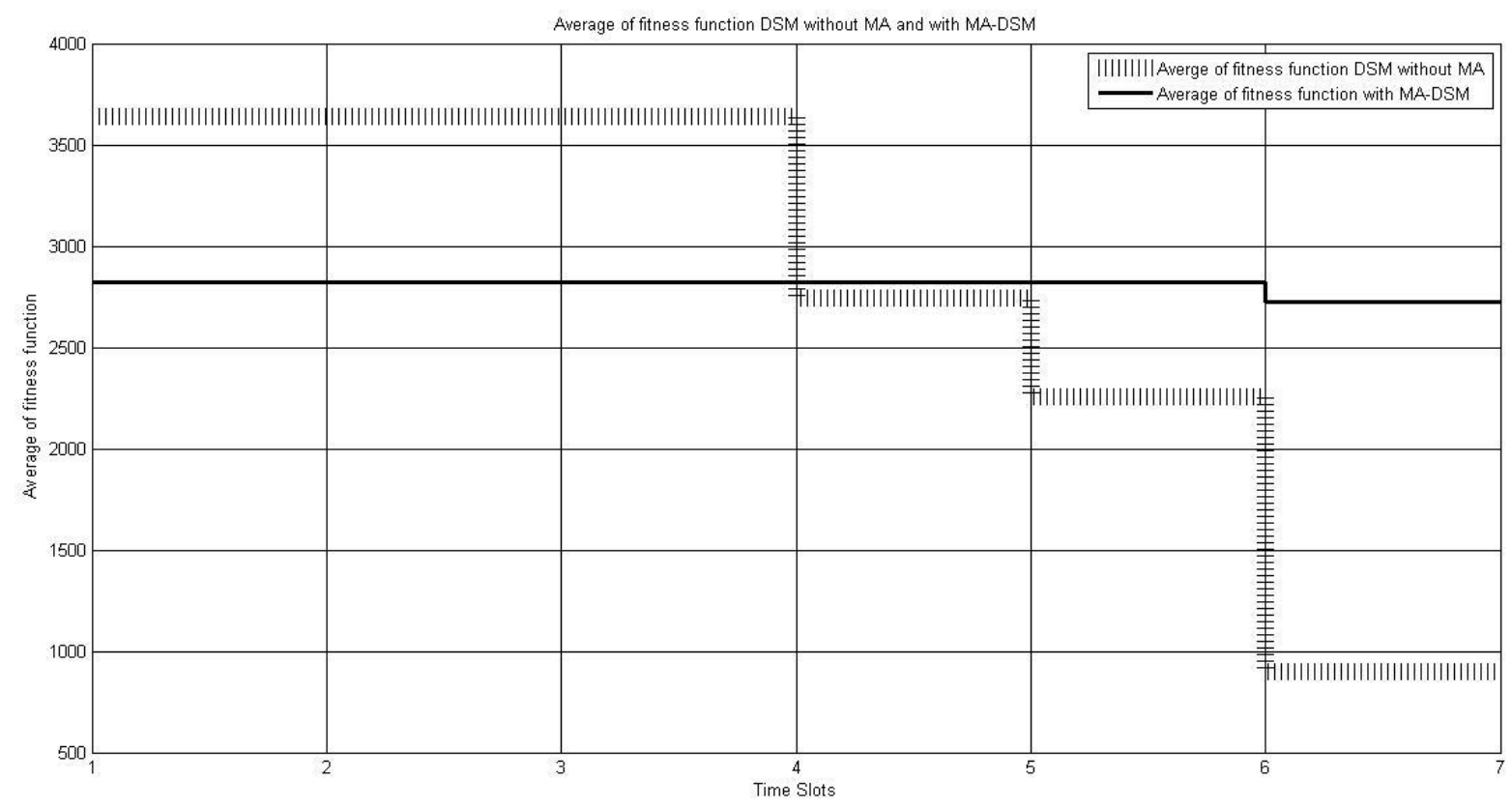

Fig. 2 Average FF evaluation - Industrial Area

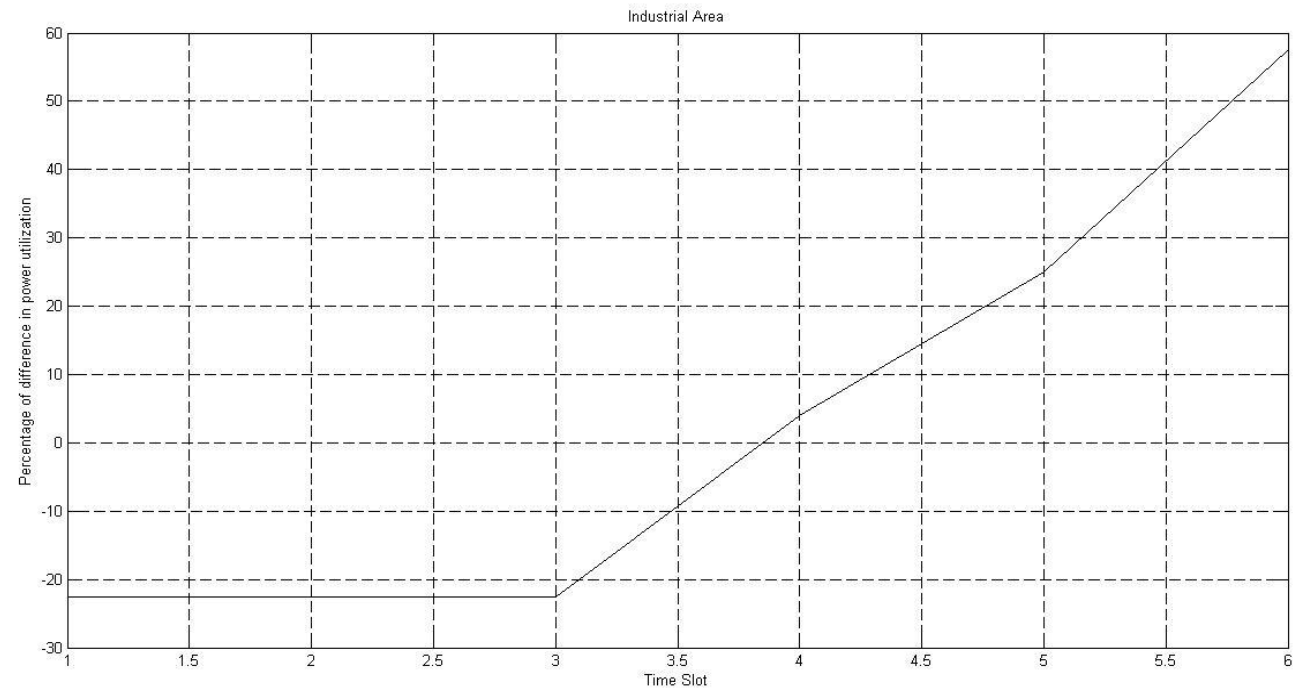

Fig. 3 Variation in utilizing power (\%) - Industrial area 


\section{Equalized Load Shaping for Demand Side Management using Memetic Algorithm}

II. Power reduction comparison between GA-DSM and MA-DSM in Industrial area

\begin{tabular}{|c|c|c|}
\hline Time Slots & GA-DSM & MA-DSM \\
\hline 1 & $-48 \%$ & $-22.6 \%$ \\
\hline 2 & $-48 \%$ & $-22.6 \%$ \\
\hline 3 & $-48 \%$ & $-22.6 \%$ \\
\hline 4 & $+22.5 \%$ & $+4.05 \%$ \\
\hline 5 & $+32 \%$ & $+25.05 \%$ \\
\hline 6 & $+75 \%$ & $+57.5 \%$ \\
\hline
\end{tabular}

\section{B. Residetial Area:}

III. comprises residential area data set. In Fig. 4, the average FF of DSM without MA shows the $1^{\text {st }}$ hour is the rush hour next two hours are off-peak hours. By applying MA-DSM, few loads are shifted to non-rush hours that is signified in the average FF with MA-DSM.

Fig. 5 represents the residential area's variation in utilizing power $(\%)$. IV. gives us the comparison of power reduction between GA-DSM and MA-DSM.

\section{Commercial Area:}

V. comprises residential area data set. In Fig. 6, the average FF of DSM without MA clearly shows that the $1^{\text {st }}$ hour is the rush hour next two hours are off-peak hours. By applying MA-DSM, few loads are shifted to non-rush hours that is signified in the average FF with MA-DSM. Fig. 7 represents the commercial area's variation in utilizing power (\%). VI. gives us the comparison of power reduction between GA-DSM and MA-DSM.

III. Data of Residential Area Loads

\begin{tabular}{|c|c|c|c|c|c|}
\hline \multirow{2}{*}{ S1.No } & \multirow{2}{*}{ Device Types } & \multicolumn{3}{|c|}{ Device Power Consumption $(\mathrm{kWh})$} & \multirow{2}{*}{$\begin{array}{c}\text { Number } \\
\text { of } \\
\text { Devices }\end{array}$} \\
\hline & & 1st Hour & $\begin{array}{l}\text { 2nd } \\
\text { Hour }\end{array}$ & 3rd Hour & \\
\hline 1 & Dryer & 1.2 & - & - & 189 \\
\hline 2 & Dry washer & 201.6 & - & - & 288 \\
\hline 3 & $\begin{array}{l}\text { Washing } \\
\text { machine }\end{array}$ & 134 & 107.2 & - & 268 \\
\hline 4 & Oven & 362.7 & - & - & 279 \\
\hline 5 & Iron & 340 & - & - & 340 \\
\hline 6 & Vacuum Cleaner & 63.2 & - & - & 158 \\
\hline 7 & Fan & 57.6 & 57.6 & 57.6 & 288 \\
\hline 8 & Kettle & 812 & - & - & 406 \\
\hline 9 & Toaster & 43.2 & - & - & 48 \\
\hline 10 & Rice-Cooker & 50.15 & - & - & 59 \\
\hline 11 & Hair Dryer & 87 & - & - & 58 \\
\hline 12 & Blender & 19.8 & - & - & 66 \\
\hline 13 & Frying Pan & 10.1 & - & - & 101 \\
\hline 14 & Coffee Maker & 44.8 & - & - & 56 \\
\hline Total & - & - & - & - & 2604 \\
\hline
\end{tabular}




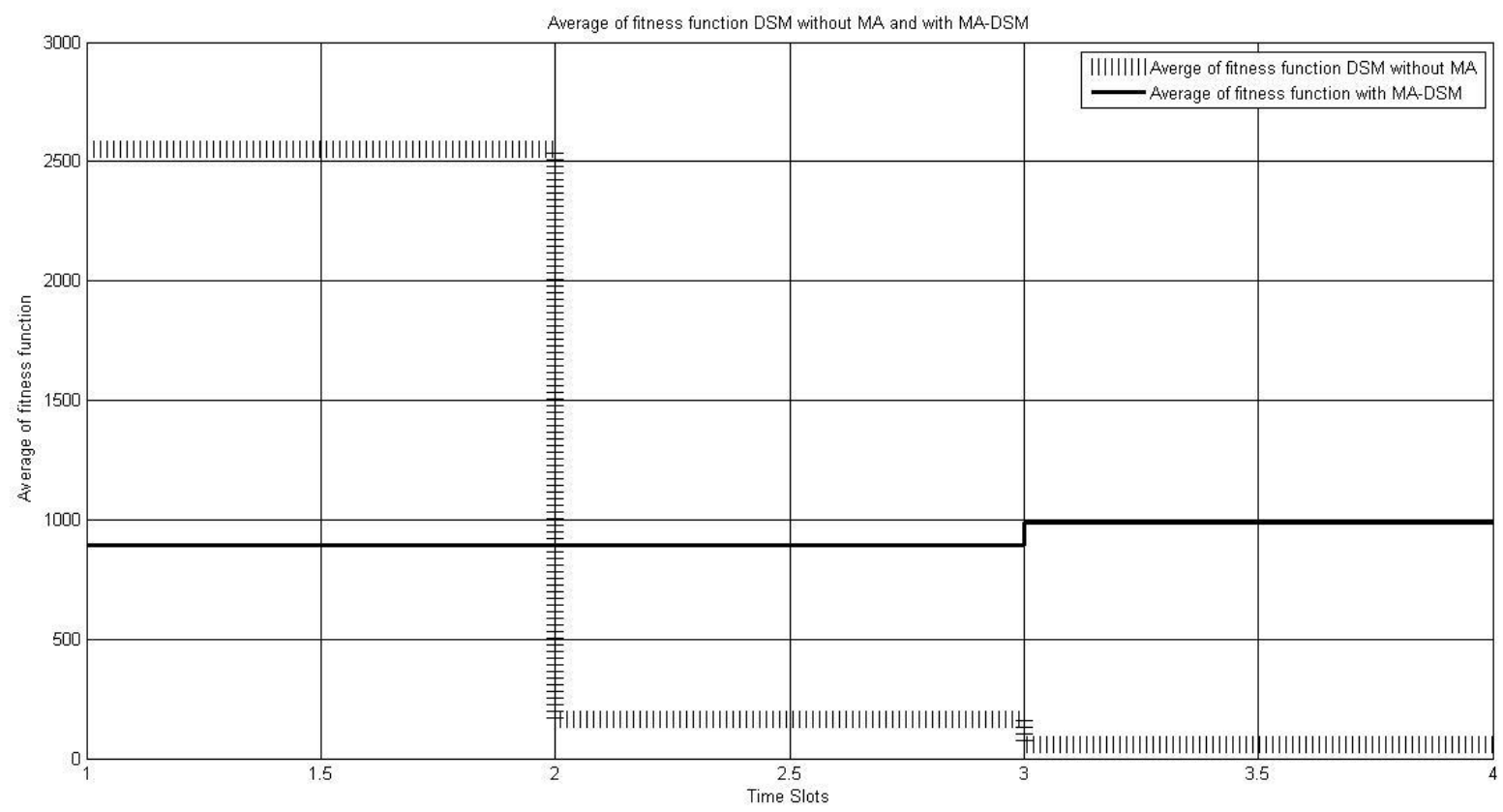

Fig. 4 Average FF evaluation - Residential Area

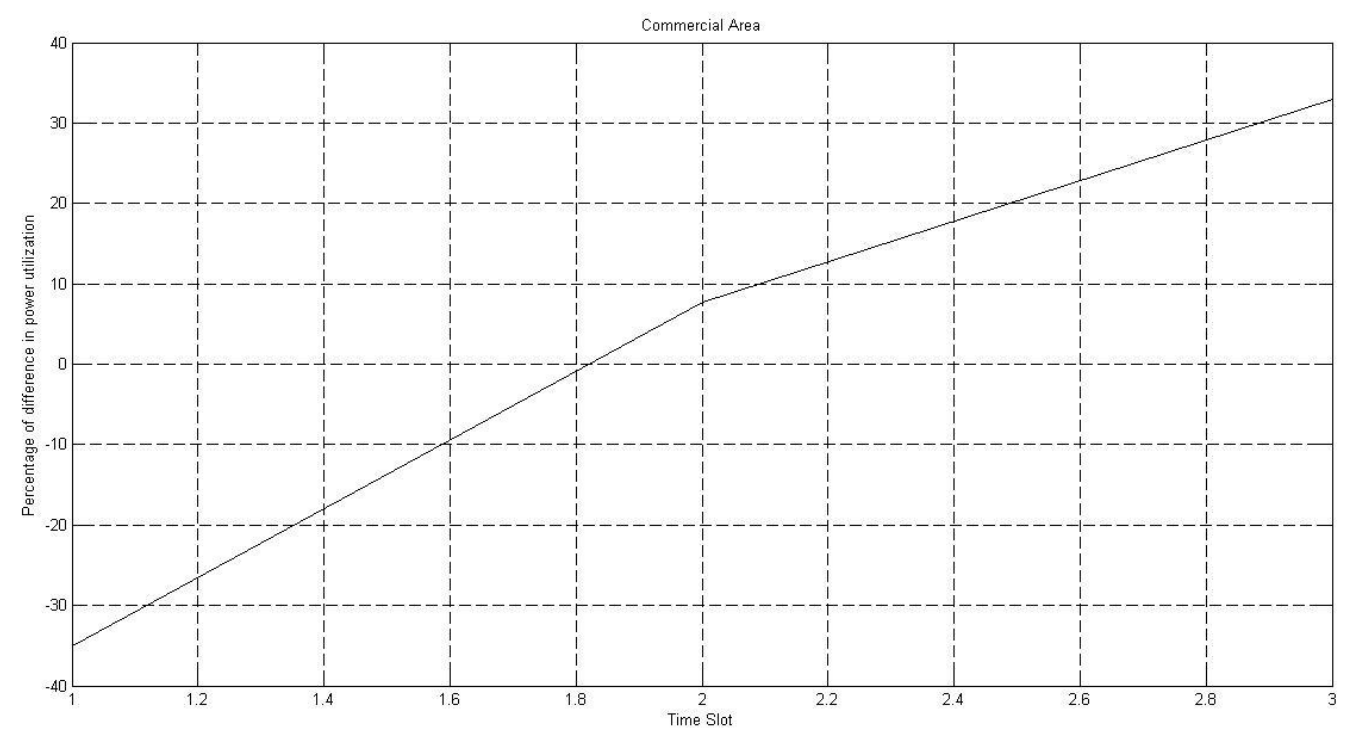

Fig. 5 Variation in utilizing power (\%) - Residential area

IV. Power reduction comparison between GA-DSM and MA-DSM in Residential area

\begin{tabular}{|c|c|c|}
\hline Time Slots & GA-DSM & MA-DSM \\
\hline 1 & $-70 \%$ & $-44 \%$ \\
\hline 2 & $+34.5 \%$ & $+22.25 \%$ \\
\hline 3 & $+46 \%$ & $+30 \%$ \\
\hline
\end{tabular}


Equalized Load Shaping for Demand Side Management using Memetic Algorithm

V. Data of Commercial Area Loads

\begin{tabular}{|c|c|c|c|c|c|}
\hline \multirow{2}{*}{ S1.No } & \multirow{2}{*}{ Device Types } & \multicolumn{3}{|c|}{$\begin{array}{c}\text { Device Power Consumption } \\
\text { (kWh) }\end{array}$} & \multirow{2}{*}{$\begin{array}{c}\text { Number of } \\
\text { Devices }\end{array}$} \\
\cline { 3 - 6 } & & 1st Hour & $\begin{array}{c}\text { 2nd } \\
\text { Hour }\end{array}$ & 3rd Hour & \\
\hline 1 & $\begin{array}{c}\text { Water } \\
\text { Dispenser }\end{array}$ & 300 & - & - & 156 \\
\hline 2 & Dryer & 409.5 & - & - & 117 \\
\hline 3 & Kettle & 369 & 307.5 & - & 123 \\
\hline 4 & Oven & 385 & - & - & 77 \\
\hline 5 & Coffee Maker & 198 & 198 & - & 99 \\
\hline 6 & Fan/AC & 325.5 & 279 & - & 93 \\
\hline 7 & Conditioner & 224 & 196 & 168 & 56 \\
\hline 8 & Lights & 174 & 152.25 & 130.5 & 87 \\
\hline Total & - & - & - & - & 808 \\
\hline
\end{tabular}

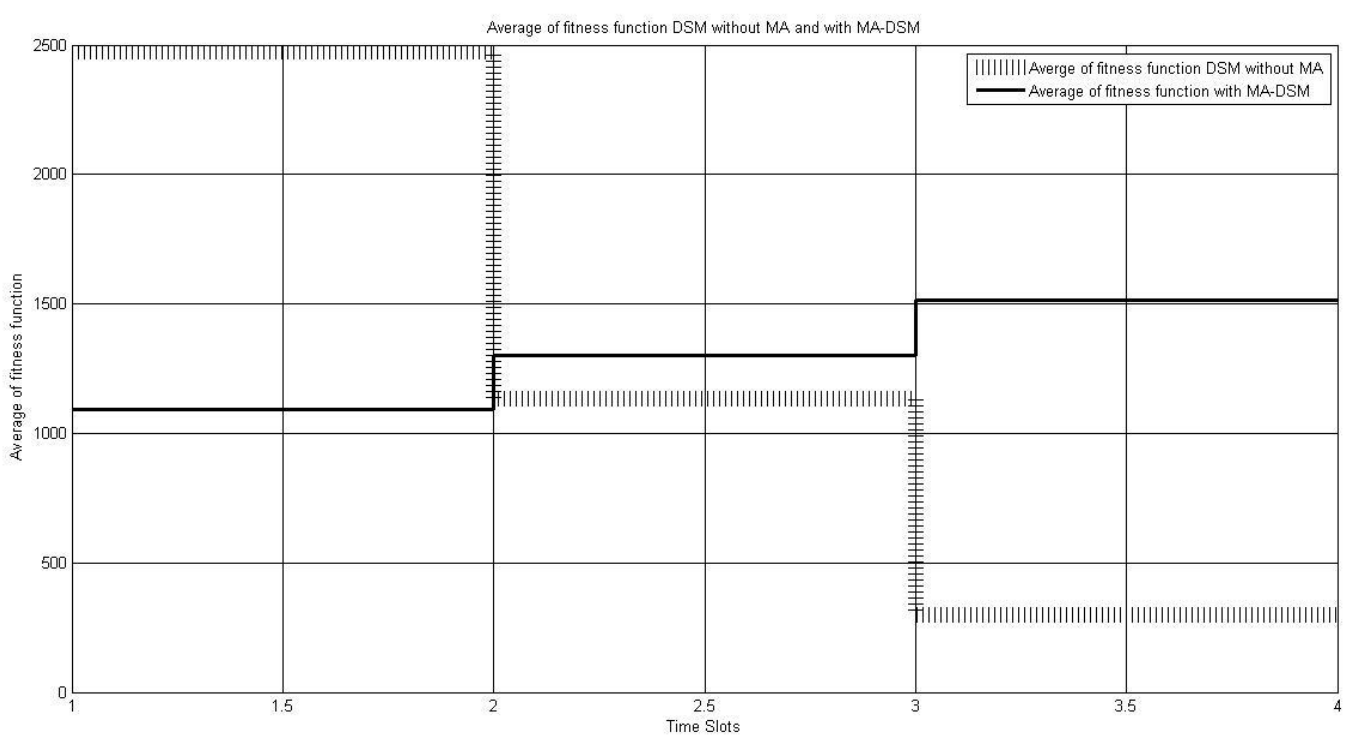

Fig. 6 Average FF evaluation - Commercial area

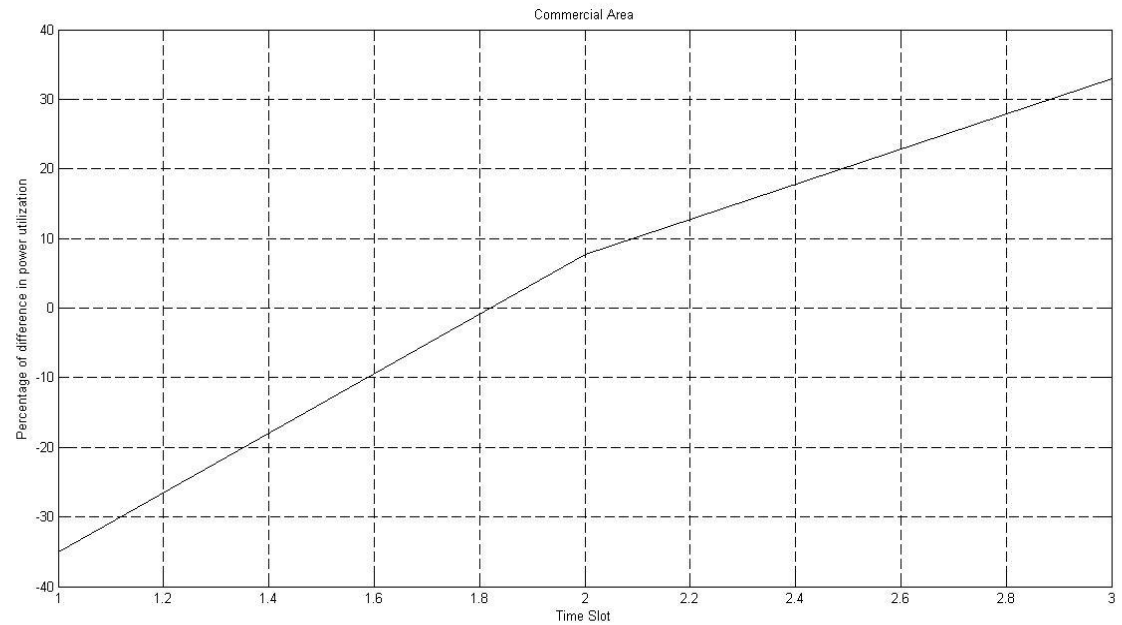

Fig. 7 Variation in utilizing power $(\%)$ - Commercial area 
VI. Power reduction comparison between GA-DSM and MA-DSM in Commercial area

\begin{tabular}{|c|c|c|}
\hline Time Slots & GA-DSM & MA-DSM \\
\hline 1 & $-64 \%$ & $-35 \%$ \\
\hline 2 & $+18 \%$ & $+7.65 \%$ \\
\hline 3 & $+45.5 \%$ & $+33 \%$ \\
\hline
\end{tabular}

\section{CONCLUSION AND FUTURE WORK}

MA-DSM important objective is equally redistributing the devices in all the time slots using flexible load shaping DSM technique is achieved. Here like GA-DSM, off-peak hour does not become peak and at the same time MA-DSM also reduces the power utilization in rush hour. This demonstrates the attainment of the given MA-DSM.

Exploitation of Cloud Computing in Smart Grid will accomplish its computational requirements. Smart Grid informations can be managed by means of Cloud Computing. Some open issues are scheduling algorithm for Demand Response (DR), security and data analysis framework in Smart Grid. To overcome these issues Cloud Computing will be integrated with SmartGrid.

\section{REFERENCES}

1. A. Mahmood, et al. "A New Scheme for Demand Side Management in Future Smart Grid Networks," Procedia Computer Science 32, 2014, 477-484.

2. G. Basso, N. Gaud, F. Gechter, V. Hilaire, and F. Lauri, “A Framework for Qualifying and Evaluating Smart Grids Approaches: Focus on Multi-Agent Technologies," Smart Grid and Renewable Energy 4.04, 2013, 333

3. V. Jayadev and K. S. Swarup, "Optimization of Microgrid with Demand Side Management using Genetic Algorithm," IET Conference on Power in Unity: a Whole System Approach, 2013, 1 - 12.

4. Elkarmi, Fawwaz and Nazih Abu Shikhah, Demand Side Management, Power System Planning Technologies and Applications: Concepts, Solutions and Management. IGI Global, 2012. 99-120.

5. Maharjan, Indra K, Demand side management: Load management, load profiling, load shifting, residential and industrial consumer, energy audit, reliability, urban, semi-urban and rural setting, LAP Lambert Academic Publ, 2010.

6. Kothari, Dwarkadas Pralhaddas, and I. J. Nagrath, Modern power system analysis, Tata McGraw-Hill Education, 2011.

7. C. Bharathi, D. Rekha, and V. Vijayakumar, "Genetic Algorithm Based Demand Side Management for Smart Grid," Wireless Personal Communications, Jan 2017, vol. 93, no. 2, pp. 481-502.

8. N. M. A. AL-Salami, "Evolutionary Algorithm Definition," American Journal of Engineering and Applied Sciences, 2009, vol. 2, no. 4, pp. 789-795.

9. N. Bélanger, G. Desaulniers, F. Soumis, J. Desrosiers, and J. Lavigne, "Weekly airline fleet assignment with homogeneity," Transportation Research Part B: Methodological 40.4, 2006, 306-318.

10. Weise T, Global optimization algorithms-theory and application, Self-Published Thomas Weise. 2009 Jun 26.

11. N. Bélanger, G. Desaulniers, F. Soumis, and J. Desrosiers, "Periodic airline fleet assignment with time windows, spacing constraints, and time dependent revenues," European Journal of Operational Research, Dec. 2006, vol. 175 , no. 3 , pp. $1754-1766$.
12. M. Stojković and F. Soumis, "An Optimization Model for the Simultaneous Operational Flight and Pilot Scheduling Problem," Management Science, Sep 2011, vol. 47, no. 9, pp. 1290-1305.

13. Sanusi, H. A., A. Zubair, and R. O. Oladele, "Comparative assessment of genetic and memetic algorithms." Journal of Emerging Trends in Computing and Information Sciences 2, no. 10 (2011): 498-508.

14. T. Logenthiran, D. Srinivasan, and T. Z. Shun, "Demand Side Management in Smart Grid Using Heuristic Optimization," IEEE Transactions on Smart Grid, Sep. 2012, vol. 3, no. 3, pp. 1244-1252.

\section{AUTHORS PROFILE}

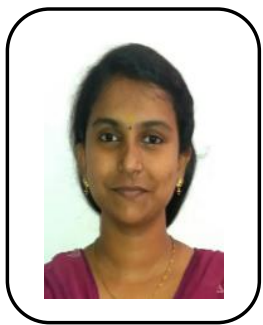

C. Bharathi received the B.E. degree for Computer Science and Engineering from Anna University, Trichy in 2011 and the M.Tech degree specialising in Multimedia Technologies from Anna University, Coimbatore in 2013. From 2009 to 2013 she has worked on various projects in Cloud Computing and Network Securities. She has also published papers in notable journals during this time. She has 5 years of working experience which includes 4 years as research associate in Vellore Institute of Technology, Chennai and 1 year as Assistant Professor in Saveetha University. She pursues her interest in Smart Grid for her Ph.D. degree from Vellore Institute of Technology, Chennai.

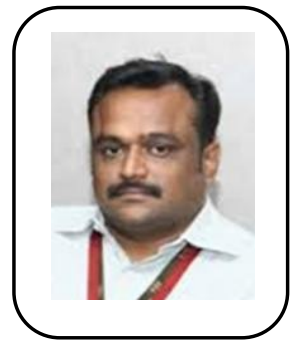

Dr. V. Vijayakumar is currently working as Professor in Vellore Institute of Technology; He has more than 17 years of experience which includes 11 years in teaching and 6 years in Industry. He is also a Division Chair of Cloud Computing Research Group; His area of research includes Grid Computing, Cloud computing, Big Data, Web semantics and also involved in the domain like Bio-medical applications-Mammogram, Autism, Immune system and other areas like key management, security issues in cloud and grid computing. During his research he is also collaborated with University of Singapore, Nan yang Technological University and Deakin University. He is the reviewer for International Journal of supercomputing -Springer and Guest Editor for international journal of Big Data intelligence and International journal of high performance communication networks. 